\title{
Use of Thienylenevinylene and Ethynyl Molecular Bridges in Organic Dyes for Dye-Sensitized Solar Cells: Implications for Device Performance
}

\author{
Laia Pellejà, ${ }^{[\mathrm{a}]}$ Rocío Dominguez, ${ }^{[\mathrm{c}]}$ Ana Aljarilla, ${ }^{[\mathrm{c}]}$ John N. Clifford, ${ }^{[\mathrm{a}]}$ Pilar de la Cruz, ${ }^{[\mathrm{c}]}$ \\ Fernando Langa, ${ }^{*[c]}$ and Emilio Palomares ${ }^{*[a, b]}$
}

\begin{abstract}
The synthesis, full characterization, and use of a series of organic dyes with thienylenevinylene and ethynyl bridges as light-harvesting chromophores in $\mathrm{TiO}_{2}$-based photoelectrochemical dye-sensitized solar cells are described. A maximum light-to-energy conversion efficiency of $\eta=5.47 \%$ under standard conditions is obtained for the organic dye denoted as FL16, which consists of an $\mathrm{N}, \mathrm{N}$-bis(4-hexyloxyphenyl)aniline donor moiety, an ethynylthieno[3,2-b]thiophene $\pi$ bridge, and a 2-cyanoacrylic acid acceptor group. The device properties are investigated by charge extraction and transient photovoltage measurements.
\end{abstract}

Organic sensitizers have pushed the efficiency of mesoporous nanocrystalline $\mathrm{TiO}_{2}$-based dye-sensitized solar cells (DSSCs) to record light-to-energy conversion efficiencies of over $12 \% .{ }^{[1]}$ For this type of solar cell to be competitive and cost effective, it is a prerequisite that the sensitizer preparation involves the minimum number of synthetic steps and can be performed on a multigram scale.

A large number of sensitizers have been developed and their chemical structures all have a "push-pull" molecular architecture, ${ }^{[2]}$ including the recently reported high efficiency porphyrins. $^{[3]}$ The fine-tuning of the "molecular bridge" between the donor (often a substituted triphenylamine) and acceptor (commonly a cyanoacrylic acid anchor) groups is achieved by molecular design through, for example, the introduction of double bonds or other different conjugated units (with the aim of broadening the absorption spectra of the dyes) or

[a] L. Pellejà,+ Dr. J. N. Clifford, Prof. Dr. E. Palomares

Institute of Chemical Research of Catalonia (ICIQ)

Avda. Païssos Catalans 16, Tarragona, E-43007 (Spain)

[b] Prof. Dr. E. Palomares

ICREA. Passeig Lluís Companys 23

E-08010, Barcelona (Spain)

E-mail:epalomares@iciq.es

[c] R. Dominguez, ${ }^{+}$Dr. A. Aljarilla, ${ }^{+}$Dr. P. de la Cruz, Prof. Dr. F. Langa Instituto de Nanociencia, Nanotecnologia y

Materiales Moleculares (INAMOL), Universidad de Castilla-La Mancha Campus de la Fábrica de Armas, Toledo E-45071 (Spain)

E-mail:fernando.langa@uclm.es

$\left.{ }^{[+}\right]$These authors contributed equally to this work.

Supporting Information for this article is available on the WWW under http://dx.doi.org/10.1002/celc.201402031. It contains experimental details for the synthesis and characterization of the dyes by ${ }^{1} \mathrm{H}$ and

${ }^{13} \mathrm{C}$ NMR spectroscopy, MALDI-MS, cyclic voltammetry, and polarizability measurements, as well as a description of the IV measurement system, charge extraction, and transient photovoltage. by increasing the number of bulky groups to minimize dye aggregation. All of these chemical strategies are aimed at enhancing the efficiency of the device. ${ }^{[4]}$

The effects that these changes have on the molecular backbone and on the interfacial charge-transfer kinetics of the device have not been studied to a great extent. In other words, more work is required to clarify the fundamental reasons for increases or decreases in the efficiency of the device on introducing new functional groups in the donor- $\pi$-acceptor $(D-\pi-A)$ organic dye.

Herein, the synthesis of a series of organic sensitizers (Scheme 1) with different bridges between the N,N-bis(4-hexyloxyphenyl)aniline (A-TPA) donor moiety and the cyanoacrylic acid acceptor/anchoring group is described.

Dyes FL15 and FL16 were synthesized as shown in Scheme 2, starting from alkyne $1 .^{[5]}$ Sonogashira coupling between 1 and 2-iodothiophene derivatives $\mathbf{2 a}$ (see the Supporting Information) and $\mathbf{2} \mathbf{b}^{[6]}$ afforded aldehydes $\mathbf{3} \mathbf{a}$ and $\mathbf{3} \mathbf{b}$ in 87 and $66 \%$ yield, respectively, after purification by column chromatography. The formation of $\mathbf{3 a}$ and $\mathbf{3} \mathbf{b}$ was confirmed in the ${ }^{1} \mathrm{H}$ NMR spectra by the presence of an aldehyde signal at $\delta=9.96 \mathrm{ppm}$ in both cases. With compounds $\mathbf{3} \mathbf{a}$ and $\mathbf{3} \mathbf{b}$ in hand, the desired dyes FL15 and FL16 were readily prepared by Knoevenagel condensation with cyanoacetic acid in the presence of piperidine and the products were obtained in satisfactory yields (FL15: $71 \%$ and FL16: 85\%).

Dyes FL17 and FL18 were prepared as shown in Scheme 3 by the Wittig-Horner reaction between A-TPA-based phosphonate $5^{[7]}$ and aldehydes $\mathbf{6}^{[8]}$ or $\mathbf{8}^{[9]}$ (in this case, under careful stoichiometric conditions). Purification by column chromatography gave $\mathbf{7}$ and $\mathbf{4 b}$ in 62 and $45 \%$ yield, respectively. The trans character of the newly formed double bond was confirmed by the coupling constant of $15.0 \mathrm{~Hz}$ in the ${ }^{1} \mathrm{H}$ NMR spectra. Aldehyde 4 a was prepared in $70 \%$ yield by Vilsmeier formylation of 7. Finally, Knoevenagel condensation of $4 \mathrm{a}$ and 4b with cyanoacetic acid yielded dyes FL17 and FL18 in 83 and $75 \%$ yield, respectively. The formation of the cyanoacrylic double bond is evidenced in the ${ }^{1} \mathrm{H}$ NMR spectra by the singlet at $\delta \approx 8.20-8.40 \mathrm{ppm}$. All new compounds were fully characterized by ${ }^{1} \mathrm{HNMR},{ }^{13} \mathrm{CNMR}$, and FTIR spectroscopy and by matrix-assisted laser desorption/ionization mass spectrometry (MALDI-MS). The data were consistent with the expected structures. For characterization data, see the Supporting Information.

The optical and electrochemical properties of the new dyes were studied by UV/Vis spectroscopy, cyclic voltammetry (CV), 

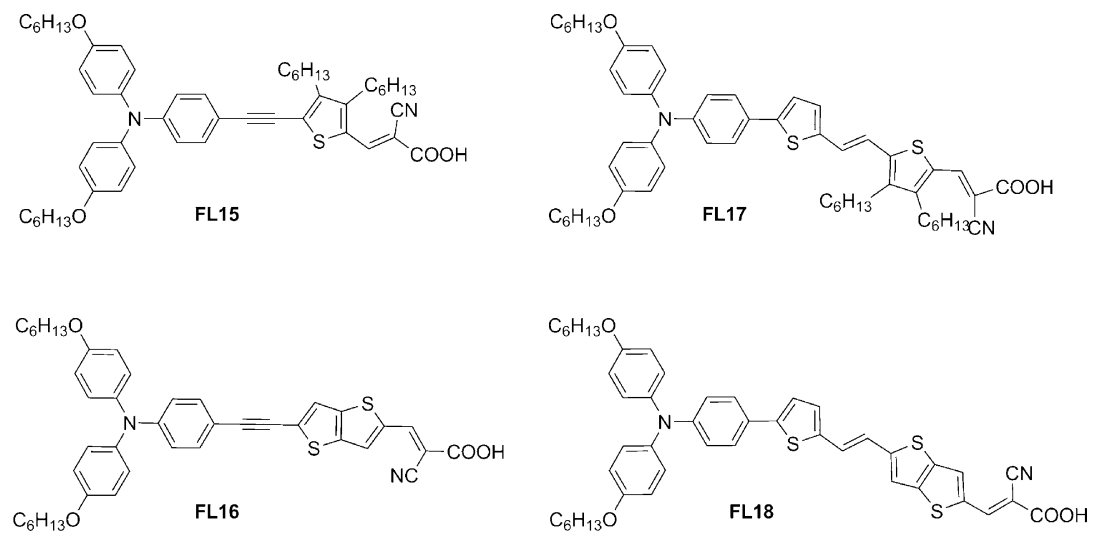

Scheme 1. Chemical structures of the sensitizers FL15-18 described herein.
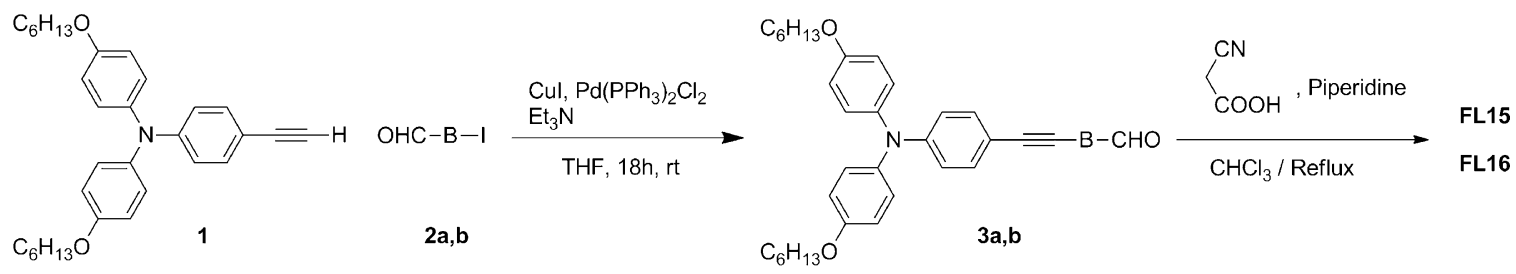

a, FL15

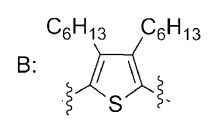

b, FL16

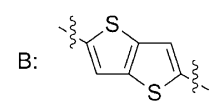

Scheme 2. Synthesis of dyes FL15 and FL16. THF= tetrahydrofuran.

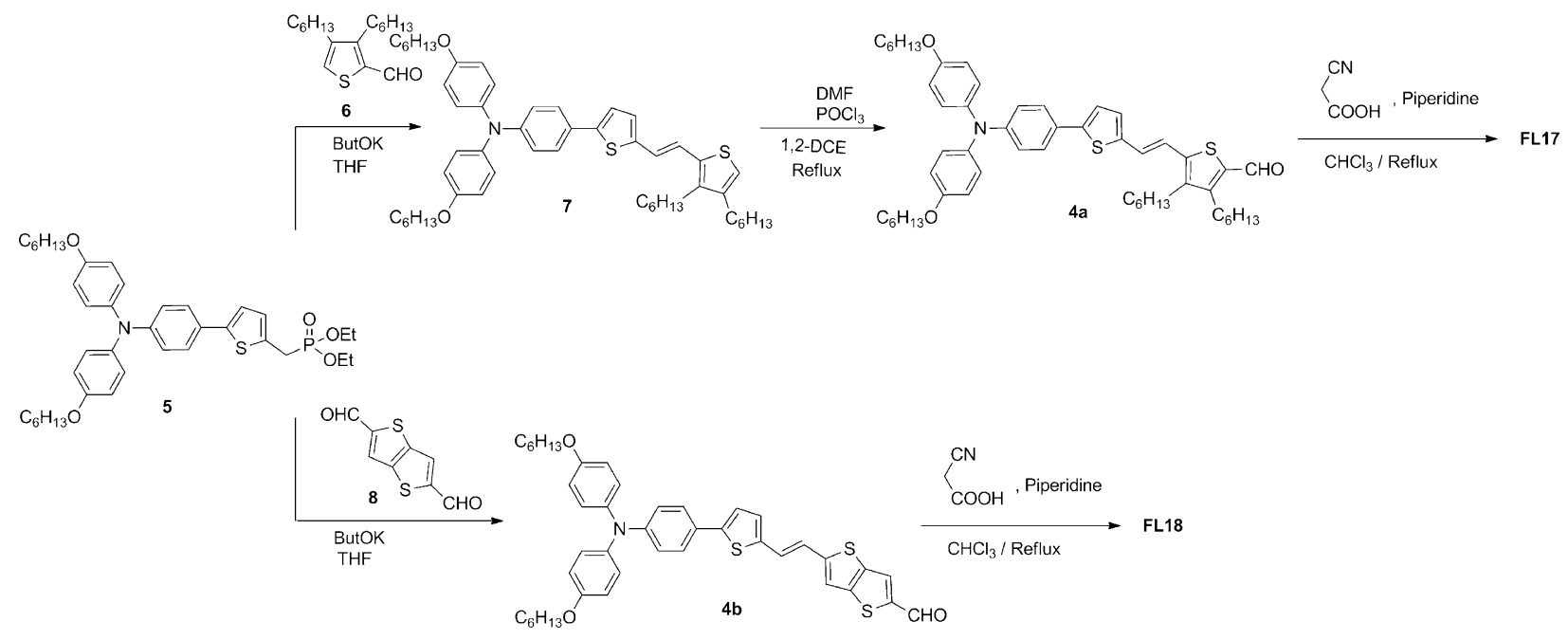

Scheme 3. Synthesis of dyes FL17 and FL18. DMF $=N, N$-dimethylformamide; 1,2-DCE =1,2-dichloroethene.

and Osteryoung square wave voltammetry (OSWV) and the data are displayed in Table 1.

In dichloromethane, all dyes show intense absorption in the visible region up to $\lambda=600-650 \mathrm{~nm}$. The two dyes with a thiophene bridge, FL15 and FL17, showed maxima at $\lambda=478$ and $532 \mathrm{~nm}$, respectively; the bathochromic shift of the absorption for dye FL17 is attributed to the increased conjugation (see
Figure 1, top). In contrast, dyes FL16 and FL18, which are based on thieno[3,2-b]thiophene, each show a broader absorption (see Figure 1 , bottom) with maxima at $\lambda=463$ and $504 \mathrm{~nm}$, respectively.

The charge-transfer character of the most intense band can be confirmed by positive solvatochromism observed upon increasing the solvent polarity. For example, in the case of dye 
Table 1. Absorption and electrochemical data for dyes FL15, FL16, FL17, and FL18.

\begin{tabular}{lllll|} 
Dye & $\lambda_{\max }[\mathrm{nm}](\log \varepsilon)^{[\mathrm{a}]}$ & $E_{\text {ox }}^{1}{ }^{[\mathrm{b}]}[\mathrm{V}]$ & $E_{\text {ox }}^{2}[\mathrm{~V}]^{[\mathrm{b}]}$ & HOMO $^{[\mathrm{cc}]}$ \\
\hline FL15 & $327(4.46), 478(4.41)$ & 0.29 & 0.80 & -5.39 \\
FL16 & $361(4.37), 463(4.41)$ & 0.30 & 0.64 & -5.40 \\
FL17 & $356(3.06), 532(4.47)$ & 0.17 & 0.55 & -5.27 \\
FL18 & $374(4.27), 504(4.41)$ & 0.21 & 0.55 & -5.31
\end{tabular}

[a] Solvent: $\mathrm{CH}_{2} \mathrm{Cl}_{2}$. [b] Measured by OSWV; $10^{-3} \mathrm{M}$ in $1,2-\mathrm{DCB} / \mathrm{CH}_{3} \mathrm{CN}$ versus the ferrocene couple $\left(\mathrm{Fc} / \mathrm{Fc}^{+}\right)$, glassy carbon, $\mathrm{Pt}$ counter electrode, $20^{\circ} \mathrm{C}, 0.1 \mathrm{M} \mathrm{Bu}_{4} \mathrm{NClO}_{4}$, scan rate $=100 \mathrm{mV} \mathrm{s}^{-1}$. [c] Calculated from $E_{\text {номо }}$ (vs. vacuum) $=-5.1-E_{\text {ox }}^{1}$ (vs. $\left.\mathrm{Fc} / \mathrm{Fc}^{+}\right)$in $\mathrm{eV}$.
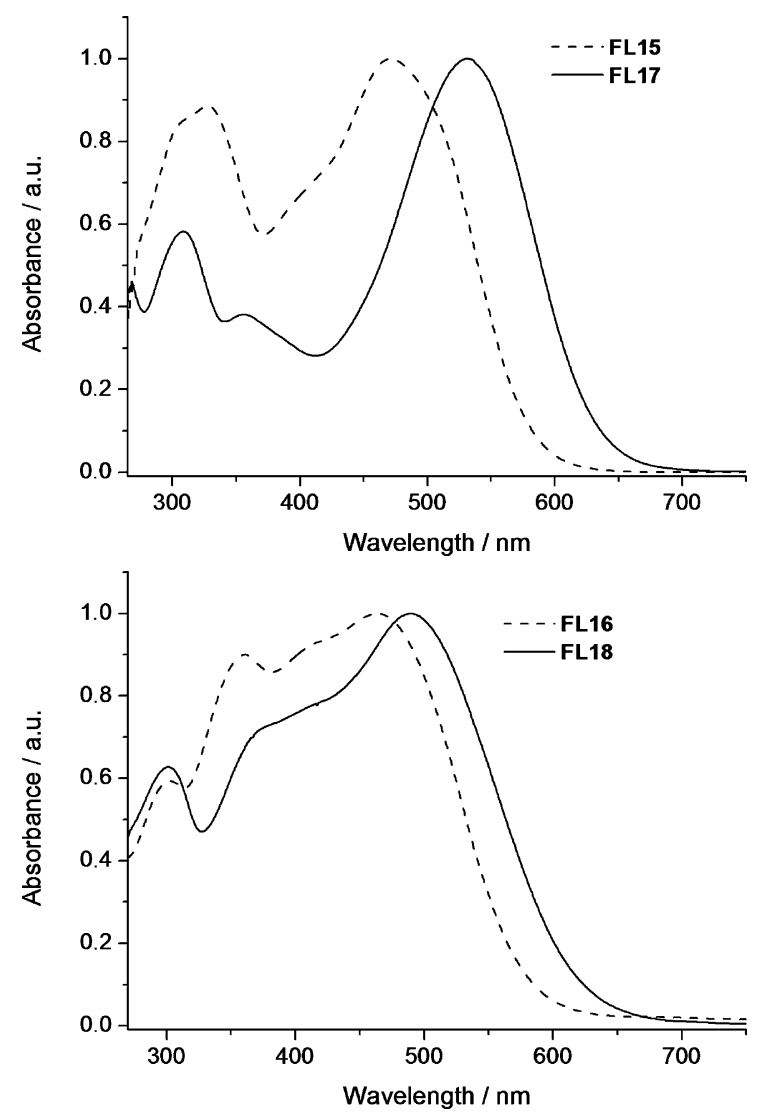

Figure 1. Normalized absorption spectra for FL15 and FL17 (top) and FL16 and FL18 (bottom) in $\mathrm{CH}_{2} \mathrm{Cl}_{2}$.

FL17, the maximum absorption peak is shifted by $21 \mathrm{~nm}$ upon increasing the solvent polarity $\left(\lambda_{\max }=510 \mathrm{~nm}\right.$ in $\mathrm{Et}_{2} \mathrm{O}, 520 \mathrm{~nm}$ in THF and $531 \mathrm{~nm}$ in $\mathrm{CH}_{2} \mathrm{Cl}_{2}$; Figure $\mathrm{S} 38$ in the Supporting Information). A higher bathochromic shift (up to $27.5 \mathrm{~nm}$ ) is observed in thieno[3,2-b]thiophene-bridged dye FL16 ( $\lambda_{\max }=$ $436 \mathrm{~nm}$ in $\mathrm{Et}_{2} \mathrm{O}, 449 \mathrm{~nm}$ in $\mathrm{THF}$, and $463 \mathrm{~nm}$ in $\mathrm{CH}_{2} \mathrm{Cl}_{2}$; Figure $\mathrm{S} 38$ in the Supporting Information). Moreover, a good correlation (correlation coefficient $>0.96$ ) between the absorption maxima and the Kamlet-Taft constants $\left(\pi^{*}\right)$ was found in all cases (see Figure S39 in the Supporting Information). The slope (S) of the Kamlet-Taft equation $\left(E=E^{\circ}+S \pi^{*}\right)$ is higher, in absolute terms, for $\operatorname{FL16}(S=7.1)$ than those for $\operatorname{FL17}(S=3.9)$ or FL18 $(S=3.7)$, corresponding the lower value to $\operatorname{FL15}(S=1.39$;
Figure S39); this indicates higher polarizability for FL16 and, consequently, better ability to transfer charge between the A-TPA moiety and the acceptor unit. As observed in Table 2, the higher $S$ values correspond to higher efficiencies of the devices.

Table 2. DSSC parameters at one sun illumination $\left(100 \mathrm{~mW} \mathrm{~cm}^{-2}\right.$ sun-simulated AM $1.5 \mathrm{G}$ irradiation). ${ }^{\left[{ }^{[a]}\right.}$

\begin{tabular}{lllll} 
Dye & $I_{\text {sc }}\left[\mathrm{mAcm}^{-2}\right]$ & $V_{\text {oc }}[\mathrm{V}]$ & $\mathrm{FF}$ & LCE \\
\hline FL15 & $6.91 \pm 0.05$ & $0.70 \pm 0.02$ & 72 & $3.5(4.5) \pm 0.2$ \\
FL16 & $10.51 \pm 0.05$ & $0.73 \pm 0.02$ & 71 & $5.5(6.7) \pm 0.2$ \\
FL17 & $10.71 \pm 0.05$ & $0.69 \pm 0.02$ & 71 & $5.2(6.3) \pm 0.2$ \\
FL18 & $12.18 \pm 0.05$ & $0.63 \pm 0.02$ & 67 & $5.2(6.2) \pm 0.2$
\end{tabular}

[a] LCE $=$ efficiency $=I_{\text {sc }}$ (short-circuit photocurrent) $\times V_{\text {oc }}$ (open-circuit voltage) $\times F F$ (fill factor)/light intensity. Values in parentheses are those without masking the devices. The LCE values are the average of no less than five devices.

The redox properties of all dyes were investigated at room temperature by $\mathrm{CV}$ and $\mathrm{OSWV}$ in 1,2-DCB/ $\mathrm{CH}_{3} \mathrm{CN}(4: 1$; Table 1 and Figures $\mathrm{S} 40-\mathrm{S} 43$ in the Supporting Information). In the cathodic region, all compounds show a first reversible oxidation wave (determined by CV) between 0.17 and $0.30 \mathrm{~V}$ (vs. Fc/ $\mathrm{FC}^{+}$); this is assigned to the TPA moiety by comparison with the oxidation potential of trimethylsilyl-protected TPA derivative $1\left(E_{\mathrm{ox}}=0.34 \mathrm{~V}\right)$. A second oxidation potential, from $0.55 \mathrm{~V}$ to $0.80 \mathrm{~V}$, is observed (see Table 1 ) and assigned to the conjugated molecular bridge (see the Supporting Information).

The $E_{\text {номо }}$ values (calculated with respect to ferrocene as a reference, $\left.E_{\text {номо }}:-5.1 \mathrm{eV}\right)^{[10]}$ were determined to be between -5.27 and $-5.40 \mathrm{eV}$ (see Table 1); this indicated that efficient dye regeneration by the $\mathrm{I}^{-} / \mathrm{I}_{3}^{-}$redox electrolyte $\left(E_{\text {redox }}=\right.$ $-4.75 \mathrm{eV}$ ) is energetically favorable for these sensitizers.

FL15-18 were used to fabricate DSSCs and these were studied under standard sun-simulated illumination conditions (AM 1.5G, $100 \mathrm{~mW} \mathrm{~m}^{-12}$ ). The photocurrent-voltage (I-V) curves recorded with illumination and in the dark are shown in Figure 2 and the device properties are shown in Table 2.

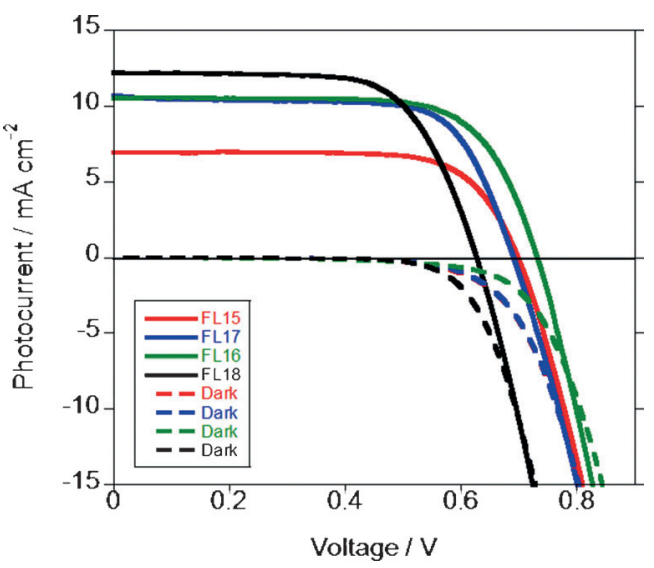

Figure 2. $I-V$ curves for devices composed of FL15-18 recorded under AM $1.5 \mathrm{G} 100 \mathrm{~mW} \mathrm{~m}^{-2}$ illumination (solid lines) and in the dark (dashed lines). 
Once the efficiency of the solar cells had been measured and the differences in performance had been noted, we performed photoinduced charge extraction and transient photovoltage measurements (details of the techniques are given in the Supporting Information). It can be observed in Figure 3
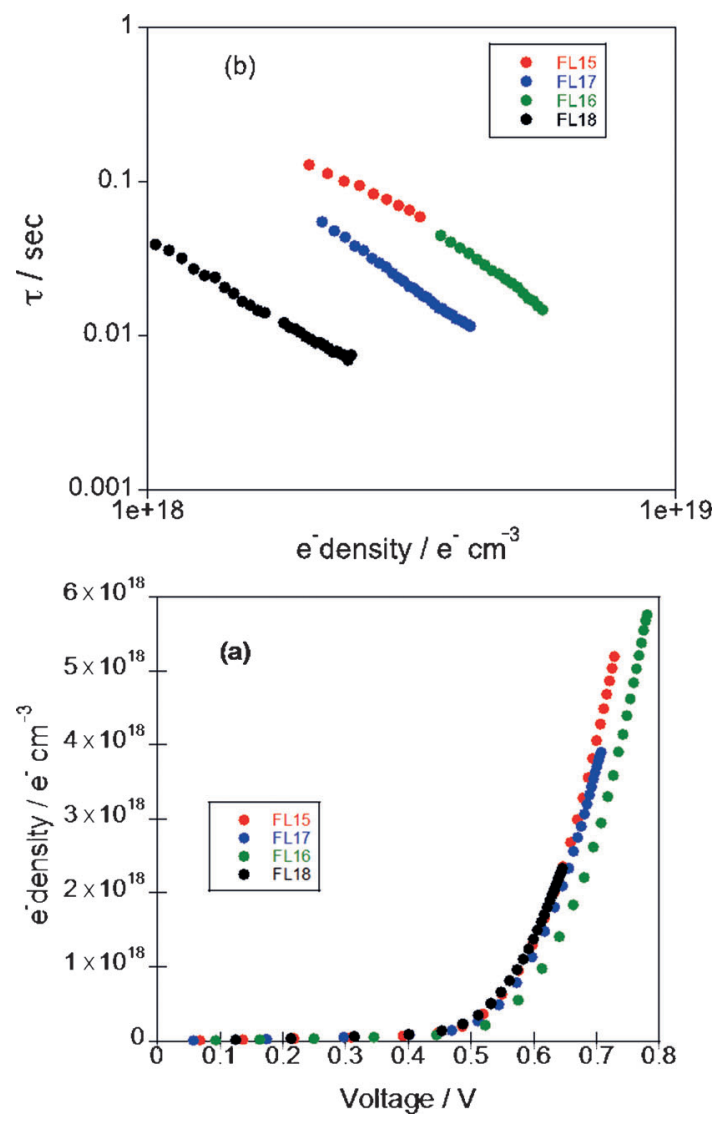

Figure 3. a) Electron density as a function of cell voltage and b) device charge lifetime, $\tau$, as a function of charge density.

that the measured charge for devices made by using dyes FL15, FL17, and FL18 lies within the same exponential curve. This observation implies that these dyes, despite their different molecular bridges, do not induce a shift of the $\mathrm{TiO}_{2}$ conduction band. On the other hand, dye FL16, which gives the device with the highest open-circuit voltage, shows a $30 \mathrm{mV}$ shift, which indicates an upward shift of the $\mathrm{TiO}_{2}$ conduction band. ${ }^{[11]}$ This observation is in good agreement with the higher polarizability measured for FL16. The formation of molecular dipoles at the $\mathrm{TiO}_{2}$ surface has been reported as one of the main factors that affects the device $V_{\text {oc }}{ }^{[12]}$ Moreover, a comparison between FL15 and FL16, both of which contain the ethynyl bridge unit, illustrates that the presence of alkyl chains in FL15 does not block the back-electron transfer reaction between photoinjected electrons at $\mathrm{TiO}_{2}$ and the oxidized electrolyte. It can be seen in Figure $3 \mathrm{~b}$ that, for the same number of charges, the charge lifetime follows the same trend ( $\tau \approx 0.1 \mathrm{~s}$ ) for FL15- and FL16-based solar cells.
Based on the information described above, it can be concluded that for the dyes studied herein, which have a pushpull structure that is very similar to most of the organic sensitizers used in DSSCs, the presence of an alkyne bridge does not consistently lead to faster recombination dynamics between photoinjected electrons at $\mathrm{TiO}_{2}$ and the oxidized electrolyte.

In this study, slower recombination dynamics in functional devices were achieved with one of the dyes (FL16) that had a triple-bond bridge in the molecular structure. Moreover, it was demonstrated that dye polarizability must also be taken into account when designing the sensitizer because the formation of dipoles at the surface of $\mathrm{TiO}_{2}$ could influence charge recombination kinetics, and thus, the device $V_{\text {oc }}$.

\section{Acknowledgements}

E.P. would like to thank the Spanish MINECO (grant CTQ201018859) and the EU for the ERCstg PolyDot. Financial support from ICREA and ICIQ is also acknowledged. F.L. thanks the Spanish MINECO grant CTQ2010-17498/BQ.R.D. thanks to MINECO for a FPU grant.

Keywords: donor-acceptor systems · dyes/pigments electrochemistry $\cdot$ photochemistry $\cdot$ solar cells

[1] A. Yella, H.-W. Lee, H. N. Tsao, C. Yi, A. K. Chandiran, M. K. Nazeeruddin, E. W.-G. Diau, C.-Y. Yeh, S. M. Zakeeruddin, M. Grätzel, Science 2011, 334, 629-634.

[2] a) N. Cai, J. Zhang, M. Xu, M. Zhang, P. Wang, Adv. Funct. Mater. 2013, 23, 3539-3547; b) M. Planells, L. Pelleja, J. N. Clifford, M. Pastore, F. De Angelis, N. Lopez, S. R. Marder, E. Palomares, Energy Environ. Sci. 2011, 4, 1820-1829; c) S.-H. Choi, D. Hwang, D.-Y. Kim, Y. Kervella, P. Maldivi, S.-Y. Jang, R. Demadrille, I.-D. Kim, Adv. Funct. Mater. 2013, 23, $3146-3155$.

[3] C.-L. Wang, C.-M. Lan, S.-H. Hong, Y.-F. Wang, T.-Y. Pan, C.-W. Chang, H.H. Kuo, M.-Y. Kuo, E. W.-G. Diau, C.-Y. Lin, Energy Environ. Sci. 2012, 5, $6933-6940$.

[4] J. N. Clifford, M. Planells, E. Palomares, J. Mater. Chem. 2012, 22, 24195 24201.

[5] P. B. Pati, S. S. Zade, Eur. J. Org. Chem. 2012, 6555-6561.

[6] M. Sato, T. Kitamura, T. Masiko, K. Unoura, J. Organomet. Chem. 2008, 693, 247-256.

[7] A. Aljarilla, L. Lopez-Arroyo, P. de La Cruz, F. Oswald, T. B. Meyer, F. Langa, Org. Lett. 2012, 14, 5732-5735.

[8] F. Oswald, D. M. S. Islam, Y. Araki, V. Troiani, P. de La Cruz, A. Moreno, O. Ito, F. Langa, Chemistry 2007, 13, 3924-3933.

[9] P. Leriche, J.-M. Raimundo, M. Turbiez, V. Monroche, M. Allain, F.-X. Sauvage, J. Roncali, P. Frere, P. J. Skabara, J. Mater. Chem. 2003, 13, 13241332.

[10] C. M. Cardona, W. Li, A. E. Kaifer, D. Stockdale, G. C. Bazan, Adv. Mater. 2011, 23, 2367-2371.

[11] P. R. F. Barnes, K. Miettunen, X. Li, A. Y. Anderson, T. Bessho, M. Gratzel, B. C. O'Regan, Adv. Mater. 2013, 25, $1881-1922$.

[12] M. Miyashita, K. Sunahara, T. Nishikawa, Y. Uemura, N. Koumura, K. Hara, A. Mori, T. Abe, E. Suzuki, S. Mori, J. Am. Chem. Soc. 2008, 130, 1787417881.

Received: February 28, 2014

Revised: April 8, 2014

Published online on June 24, 2014 